\title{
Downs cephalometric norms for Iraqi adolescents in Mosul City
}

\author{
Fadhil Y JASIM * \\ Alaa D AL - DAWOODY **
}

\begin{abstract}
The purpose of this study is to develop cephalometric standards for Iraqi adolescents in Mosul City, using Downs' analysis, and to compare them with those of white Americans.

The lateral cephalometric radiographs (108) Iraqi adolescents (57 males and 51 females) with age range was (12) to (15) years (with a mean of 13.7 years) were carried out. The subjects were chosen on the bases of having class I normal occlusion and well-balanced faces.

Measurements were taken for all dento-skeletal variables in Downs' analysis. Norms were established for the Iraqi sample and the comparison between both sexes was carried out. No significant difference was demonstrated between males and

Females. When the measurements of this study were compared with Downs'original data for white Americans, the Iraqi adolescents showed a highly significant greater values of facial convexity angle, mandibular plane angle, $Y$-axis angle, occlusal plane angle, lower incisors inclination to the occlusal plane and to the mandibular plane and the distance of upper incisors to Apog line. The interincisal angle and facial angle were significantly higher in Downs' original standards than the present study.
\end{abstract}

Key words: Cephalometric standards, Downs' Analysis, normal occlusion, balanced face.

| الخلاصة

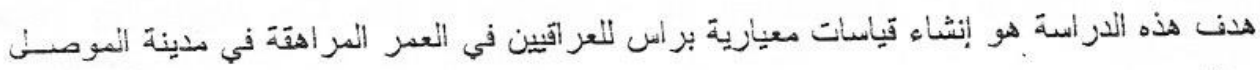

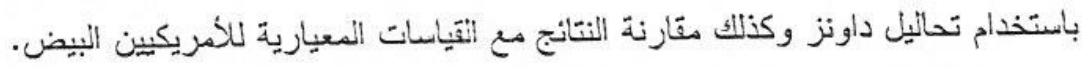

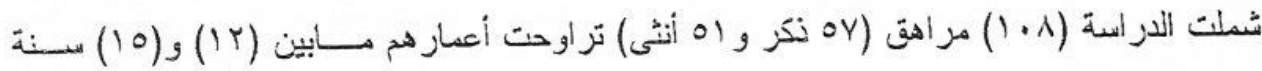

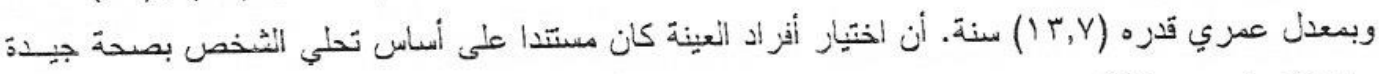

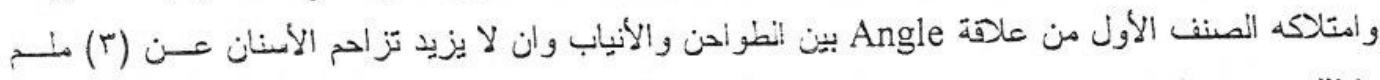

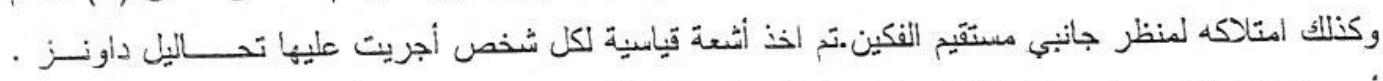

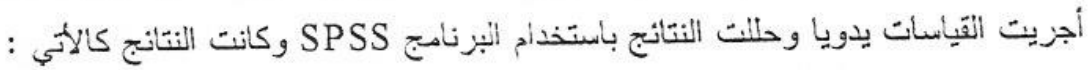

*Fadhil Yassin JASIM; BDS, CES, DSO: Assistant Prof.

** Alaa Dawood AL-DAWOODY; BDS, MSc: Assistant Lecturer

Department of Pedodontics, Orthodontics and Preventive Dentistry, College of Dentistry, University of Mosul, Mosul, IRAQ. 


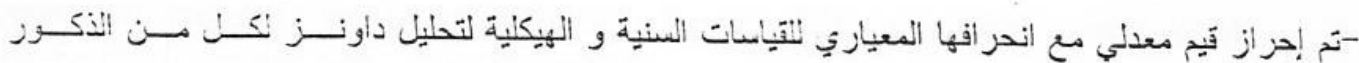

$$
\begin{aligned}
& \text { والإناث وكنلك العينة الكلية. } \\
& \text { - سم يظهز أي فرق معنوي للقياسات بين النكوز والإناث. }
\end{aligned}
$$

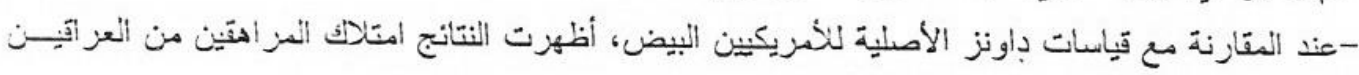

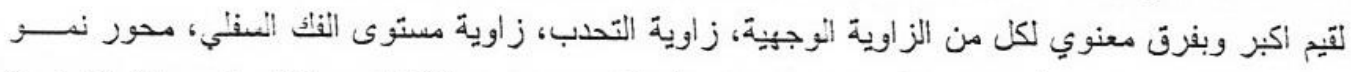

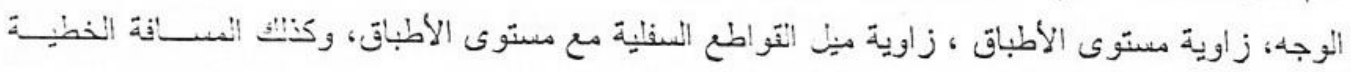

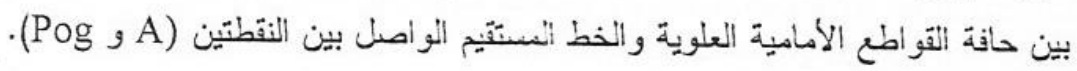

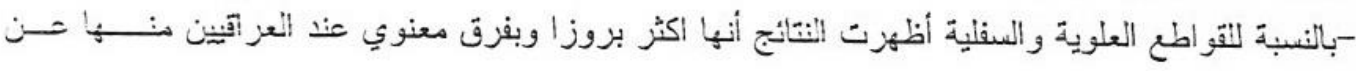

$$
\begin{aligned}
& \text { الأمريكان. }
\end{aligned}
$$

\section{INTRODUCTION}

Cephalometric studies of different ethnic groups have found that normal measurements of one group should not be considered normal for other racial groups. Different racial groups must be treated according to their own individual characteristics (1).

Uesato et al. (2) showed that the denture bases of the Japanese and Japanese Americans were positioned slightly more posterior in relation to the cranial bases than those of the Caucasians. The ANB angle of (3) degrees indicated that the Japanese skeletal pattern tends to be more in class II category than in the Caucasian pattern. The relationship of the maxillary central incisor to the line NA was virtually identical with that of the Caucasian. The mandibular central incisor was slightly more procumbent than that of the Caucasian.

Aboul-Azm and Fahmy ${ }^{(3)}$ found those Egyptian adults when compared to white American adults had a greater bimaxillary protrusion and a more acute interincisal angle.

Hajighadimi et al. ${ }^{(4)}$ found that the skeletal pattern of the Iranian children was more retrusive than that of American Caucasian. Iranian group had a straighter bony profile. The mandibular plane angle and the occlusal plane angle were higher and The dental pattern of the Iranian sample was more procumbent in the Iranian group than the Steiner's norms.

Jung ${ }^{(5)}$ noted that the Chinese exhibits a relatively more prognathic lower face - maxilla and mandible and class II tendency than Caucasian.

Bishara and Fernandez ${ }^{(6)}$ showed that The SNB and SNPog angles were significantly larger for the North Mexican girls, indicating a relatively more protrusive mandible than the adolescent Iowa female.

Pereira et al. ${ }^{(7)}$ found that the anteroposterior relations of the mandible and maxilla (ANB angle) of the Sambaquis were slightly more divergent than the reference norms applied to modern Caucasoid population.

Park et al. ${ }^{(8)}$ found that Koreans have a similar skeletal pattern, slightly larger facial convexity, a more protrusive and labially inclined maxillary and mandibular incisors than Caucasians.

Bishara et al. ${ }^{(9)}$ found that Egyptian have a tendency toward bimaxillary dental protrusion and a decreased overbite as compared with Iowa boys. Egyptian girls have a relatively more convex profile and a tendency toward mandibular protrusion. 
Munandar and Snow (10) found that Deutro-Malay Indonesians were significantly different from Caucasians, Chinese-Malays, and North- Indians for skeletal measures of the angle of convexity and $\mathrm{Y}$ axis and for dental variables of interincisal angle and upper incisors to A-Pog.

Miyajima et al. ${ }^{(11)}$ found that the facial axis angle was more vertical in Japanese subjects than European-American ancesotry, indicating a more downward direction of facial development. Japanese were also more protrusive dentally.

The purpose of this study is to establish cephalometric norms for Iraqi adolescents in Mosul City by means of Downs' analysis ${ }^{(12-14)}$ and comparing the data to downs' original standards for white American.

\section{MATERIALS AND METHODS}

The sample consists of (108) students, (57) males and (51) females in Mosul City. Age range of the sample was (12) to (15) years with a mean of (13.7) years.

\section{Criteria of Sample Selection}

Certain criteria were used in the selection of subjects, they are:

(1) Full complement of permanent dentition in both jaws (except for the third molars).

(2) Class I molar and canine relationships, which are based on Angle Classification.

(3) No or mild crowding (less than three millimeters).

(4) Normal overjet and overbite (ranging from 2-4 mm).

(5) No apparent dental or skeletal discrepancies and asymmetries.

(6) No history of facial trauma, orthodontic treatment, extensive restorative dentistry and orthognathic or maxillofacial surgery.

(7) Good health with no systemic disease.

(8) No TMJ problems.

(9) No history of parafunctional oral habits or mouths breathing.

(10) The subjects were of Iraqi origin with their parents and grandparents were born in the center of Mosul City.

One hundred thirty six subjects met these criteria in the preliminary examination and were asked to report to the College of Dentistry, Mosul University for further examination and for taking cephalometric radiographs. Of these (136) subjects, (18) chose not to participate in the study, and after taking cephalometric radiographs, (10) subjects were excluded because of poorly exposed and / or developed cephalograms, non-occluding teeth and inability to locate the anatomical landmarks accurately on the radiograph. The data of (108) persons were included in the study ( 57 male and 51 female).

\section{Cephalometric Analysis}

Downs' analysis ${ }^{(12-14)}$ was used for tracing the lateral head film for the subjects. Each subject was traced by one investigator and checked for accuracy by another. Measures of dento-skeletal form were calculated by computer and tabulated by gender into skeletal and dental relationships. 


\section{Cephalometric Landmarks}

\section{Skeletal Landmarks (figure 1)}

1. Point $\mathbf{S}$ (Sella): mid point of the hypophyseal fossa (sella turcica).

2. Point $\mathbf{N}$ (Nasion): the most anterior point of the frontonasal suture in the median plane.

3. Point $\mathrm{P}$ (Porion): the most superior point of the external auditory meatus.

4. Point Or (Orbitale): the lower most point on the inferior or bony margin of the orbit.

5. Point Gn (Gnathion): the most outward everted point on the profile curvature of the symphysis of the mandible.

6. Point Go (Gonion): the most outward and everted point on the angle formed by the junction of the ramus and body of the mandible on its posterioinferior aspect.

7. Point Pog (Pognoion): the most anterior point on the symphysis of the mandible.

8. Point A (Subspinale): an arbitrary measure point taken at the innermost curvature from the anterior nasal spine to the crest of the maxillary alveolar process.

9. Point B (Supramentale): An arbitrary measure point on the anterior profile curvature from the mandibular anthropometric landmark pogonion (Pog) to the crest of the alveolar process.

10. Point Me (Menton): Most inferior point on the symphysis of the mandible.

\section{Dental Landmarks}

1. Point U1 (incisor superius): Incisal tip of the crown of the most anterior maxillary central incisor.

2. Point L1 (incisor inferius): Incisal tip of crown of the most anterior mandibular central incisor.

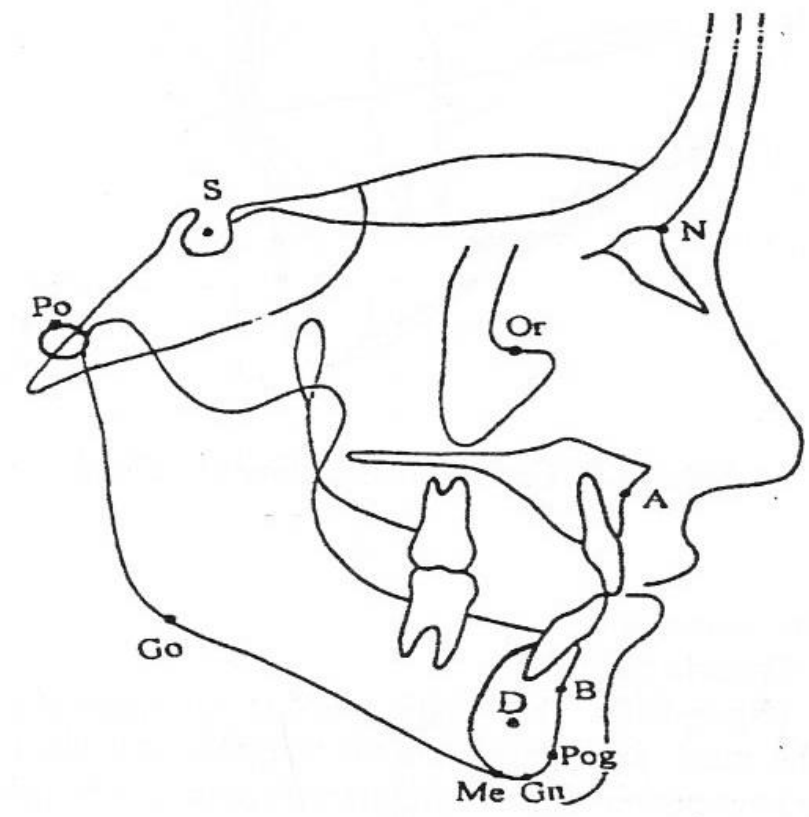

Figure (1): Cephalometric landmarks 


\section{Cephalometric Lines and Planes (figure 2)}

1. Frankfort Horizontal Plane (FH): This facial plane connects the lowest point of orbit (Orbitale) and the superior point of the external auditory meatus (porion), machine porion.

2. Occlusal Plane (OP): This denture plane bisects the posterior occlusion of the permanent molars and premolars and extends anteriorly. In an ideal situation, the occlusal plane also bisects the occlusion of the incisor teeth.

3. Mandibular Plane (MP): A line between gonion (Go) and gnathion ( $\mathrm{Gn}$ ) (Steiner). In Downs' analysis the mandibular plan is measured between gonion (Go) and Menton (Me).

4. Facial Plane (N-Pog): A line from the anterior point of the frontonasal suture $(\mathrm{N})$ to the most anterior point of the mandible (Pog).

5. Incisal Axes: The long axes of the maxillary and mandibular central incisors.

6. Dental base limit $(\mathrm{AB})$ : A line drawn through points $\mathrm{A} \& \mathrm{~B}$.

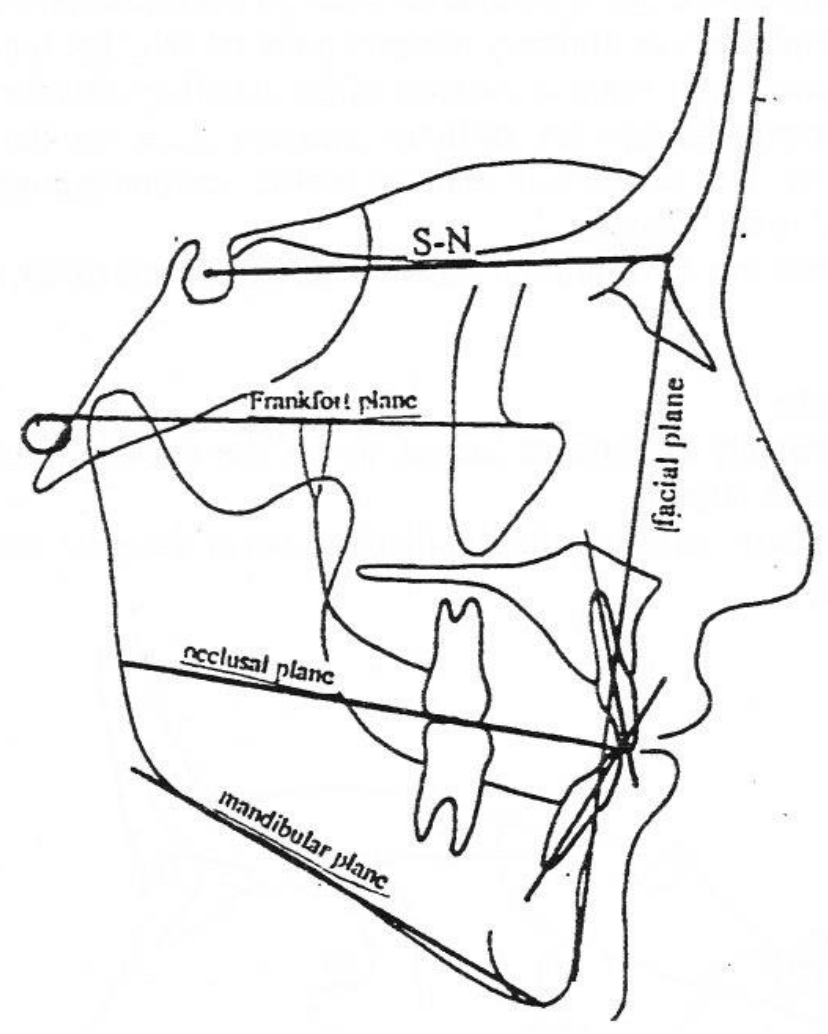

Figure (2): Cephalometric planes and lines

\section{Cephalometric measurements}

\section{Downs' Skeletal Criteria (figure 3)}

1. Facial Angle (Npog-FH): This angle gives an indication of the anteroposterior position of the most anterior point of the mandible. It is the inside inferior angle formed by the intersection of the Frankfort horizontal and facial plane.

2. Angle of Convexity (N-A-Pog): This angle reveals the convexity or (concavity) of the skeletal profile. It is formed by the intersection of a line from nasion $(\mathrm{N})$ to Point (A) with a line from point (A) to Pogonion (Pog). 
3. A-B Plane Angle (A-B to Npog): This angle reveals the maxillo-mandibular relationship of the apical bases relative to the facial line.

4. Mandibular Plane Angle (MP to FH): It is intersection between mandibular plane (Go-Me) and the Frankfort horizontal plane (FH).

5. Y-Axis Angle (S-Gn to $\mathbf{F H})$ : This angle is often called growth axis angle. It is formed by the intersection of a line from sella turcica (S) to Gnathion (Gn) with Frankfort horizontal plane (FH).

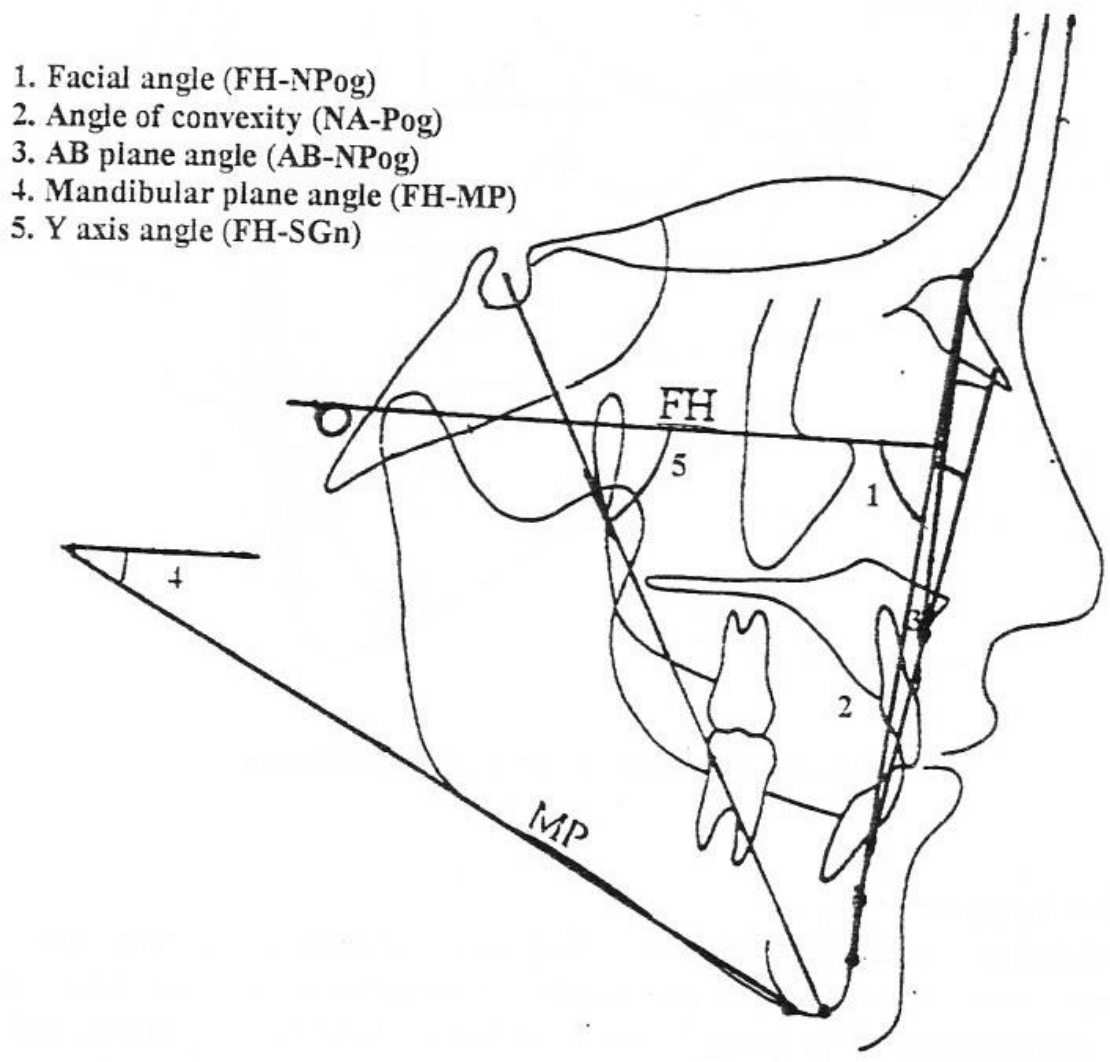

Figure (3): Down's skeletal measurements

\section{Downs' Dental Criteria (figure 4)}

1. Occlusal Plane Angle (OP to $\mathrm{FH}$ ): this measurement indicates the angulation of the plane of occlusion relative to the Frankfort plane.

2. Interincisal Angle (U1-L1): This angle related the angular position of the long axis of the upper and lower central incisors to each other.

3. Lower Incisor to Occlusal Plane (L1-OP): This angle indicates the inclination of the lower central incisor relative to the occlusal plane.

4. Lower Incisor to Mandibular Plane (L1-MP): This angle reveals the inclination of the lower central incisor relative to the mandibular plane. 
5. Upper Incisor to A-Pog Line (U1 to APog): This is only linear measurement in Downs' analysis. It gives an indication of the antero-posterior position of the incisal edge of the upper incisor relative to the A-Pog line.

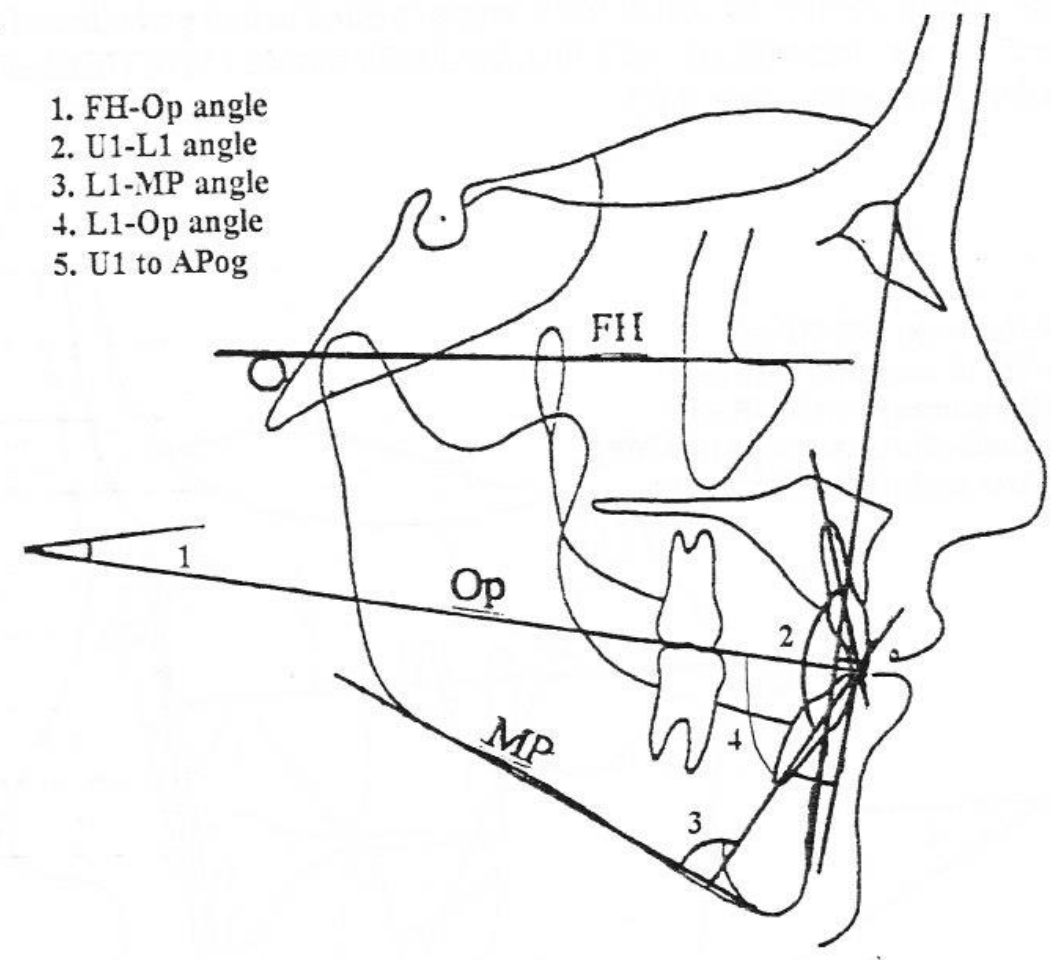

Figure (4): Down's dental measurements

\section{Statistical Analysis}

Standard descriptive statistics (minimum, maximum, means, and standard deviations) were calculated for the sample. Comparison between Iraqi males and females was established by using F-test. Comparison between the sample and Downs' original standards for white Americans was conducted by means of $t$-test.

\section{RESULTS}

Table (1) presents the minimum, maximum, means and standard deviations of the dento-skeletal measurements for the Iraqi adolescents in Mosul City.

Table (2) shows that the sex differences were small and no statistical significance was noted in the skeletal and dental measurements.

In table (3), The Iraqi subjects show greater values than the White Americans population in the following measurements: Angle of convexity (N-A-Pog), mandibular plane angle (FH-GoMe), growth axis angle (FH-SGn), occlusal plane angle (FH-OP), lower incisor to occlusal plane (L1-OP), lower incisor to mandibular plane (L1-MP) and upper incisor to A-pog line (U1 to Apog). The Iraqi adolescents show lower values of interincisal angle (L1-U1) and facial angle (FH-Npog) as compared to the White Americans sample of Downs'. These differences are highly significant $(p<0.01)$. 
Table (1): Descriptive statistics: minimum, maximum, mean and standard deviation for Iraqi adolescents using Downs' skeletal and dental analyses

\begin{tabular}{|c|c|c|c|c|}
\hline Itaratoses" & 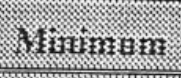 & 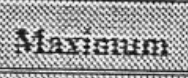 & it & $53=$ \\
\hline \multicolumn{5}{|l|}{ STctetetaf 1 feassererzents: } \\
\hline FH-Npog & 75.0 & 92.0 & 84.84 & 3.54 \\
\hline N-A-Pog & -10.0 & 13.0 & 2.79 & 4.16 \\
\hline $\mathrm{AB}-\mathrm{NP} \circ \mathrm{g}$ & -10.0 & 1.0 & -3.81 & 2.51 \\
\hline $\mathrm{MPA}(\mathrm{FH}-\mathrm{GoMe})$ & 20.0 & 39.0 & 28.0 & 4.51 \\
\hline FH-SGn & 55.0 & 69.5 & 62.50 & 3.37 \\
\hline \multicolumn{5}{|l|}{ 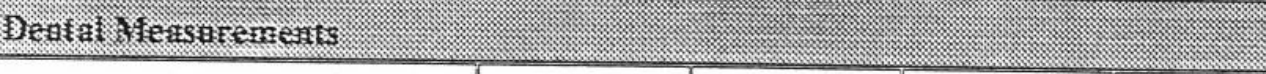 } \\
\hline $\mathrm{FH}-\mathrm{OP}$ & 4.0 & 18.5 & 11.56 & 3.34 \\
\hline U1-Ll & 111.0 & 136.0 & 122.66 & 5.64 \\
\hline L1-OP & 16.0 & 35.0 & 24.88 & 5.01 \\
\hline L1-MP & 85.0 & 108.0 & 98.03 & 5.66 \\
\hline U1 to $\mathrm{APog}(\mathrm{mm})$ & 1.5 & 12.0 & 7.43 & 2.21 \\
\hline
\end{tabular}

* Measurements in degree except U1 to APog in millimeters

** SD: Standard deriation

\section{DISCUSSION}

Most Iraqi cephalometric standards are developed for aduits ${ }^{(15,16,17)}$. Their standards may be of value for orthognathic surgery. Cephalometric standards for adolescent Iraqi males and females are urgently needed, because most persons requiring orthodontic treatment are in this age range. These standards will be of value in the diagnosis, treatment planning and treatment of dentofacial anomalies in Iraqi adolescents.

\section{Skeletal Relationships}

This study showed no significant differences in all skeletal measurements for Downs' analysis between males and females of Iraqi adolescents. However, the males revealed slightly larger mean values of N-A-Pog. FH-SGn and AB-NPog angles than those of females, indicating that the Iraqi boys have a more convex profile and a more downward growth of the mandible than those of Iraqi females. Females showed a greater mean value than males for facial angle indicating a more anterior position of female's mandible related to cranium when compared to males (table 2).

When the mean values of the sample of the present study were compared to the mean values of the white Americans, the results showed a significant difference for all measurements of Downs' analysis, except AB-plane angle (table 3).

The mean value of facial angle (FH-NPog) showed a lower value than that of White Americans. This indicates a posterior position of the mandible in relation to the cranium when compared with an average of $\left(87.7^{\circ}\right)$ of Downs' group. The mean value of the angle of convexity ( $\mathrm{N}-\mathrm{APog})$ was $\left(+2.79^{\circ}\right)$ in comparison to zero of Downs. 
This difference indicates that the maxillary part of the face was protrusive in Iraqi adolescents in comparison to Caucasians (White American's sample). The mean value of mandibular plane angle (FH-GoMe) was larger in Iraqi sample, indicating that Iraqi adolescents had high steepness of the mandibular base. The value of $Y$-axis angle (FH-SGn) was higher in Iraqi sample $\left(62.5^{\circ}\right)$ in comparison with $\left(59.4^{\circ}\right)$ of White Americans. This demonstrates that Iraqi adolescents had a more retrusive mandible, relative to cranium, as compared to White Americans.

Table (2): Comparison between Iraqi males and females using Downs' variables

\begin{tabular}{|c|c|c|c|c|c|c|c|}
\hline 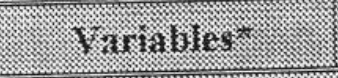 & Sex: & Min. & 1.ax. & M.rin & $313=:$ & 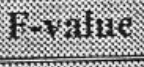 & 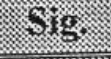 \\
\hline \multicolumn{8}{|c|}{ 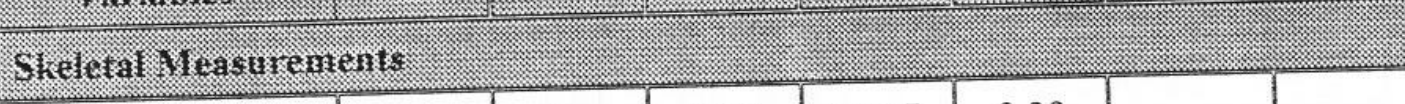 } \\
\hline \multirow{2}{*}{ FH-Npog } & M & 75.0 & 92.0 & 84.37 & 3.39 & \multirow{2}{*}{2.186} & \multirow{2}{*}{$\mathrm{NS}^{* * *}$} \\
\hline & F & 78.0 & 92.0 & 85.37 & 3.67 & & \\
\hline \multirow{2}{*}{ N-A-Pog } & M & -10.0 & 13.0 & 2.98 & 4.87 & \multirow{2}{*}{0.253} & \multirow{2}{*}{ NS } \\
\hline & F & -5.0 & 8.0 & 2.58 & 3.21 & & \\
\hline \multirow{2}{*}{ AB-Npog } & M & -10.0 & 1.0 & -3.92 & 2.80 & \multirow{2}{*}{0.234} & \multirow{2}{*}{ NS } \\
\hline & F & -10.0 & 0.0 & -3.69 & 2.16 & & \\
\hline \multirow{2}{*}{ MPA-(FH-GoMe) } & $\mathrm{M}$ & 20.0 & 37.5 & 27.83 & 4.62 & \multirow{2}{*}{0.163} & \multirow{2}{*}{ NS } \\
\hline & $\mathrm{F}$ & 20.5 & 39.0 & 28.19 & 4.42 & & \\
\hline \multirow{2}{*}{ FH-SGn } & M & 56.0 & 69.5 & 62.87 & 2.95 & \multirow{2}{*}{1.482} & \multirow{2}{*}{ NS } \\
\hline & $\mathrm{F}$ & 55.0 & 69.0 & 62.08 & 3.78 & & \\
\hline \multicolumn{8}{|c|}{ 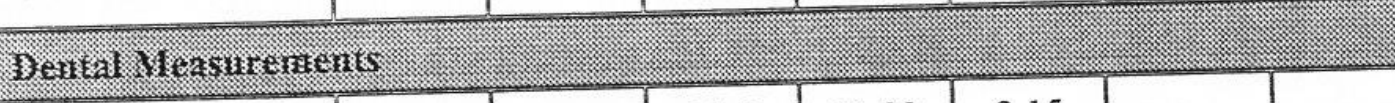 } \\
\hline \multirow{2}{*}{ FH-OP } & M & 5.0 & 18.5 & 11.88 & 3.15 & \multirow{2}{*}{1.123} & \multirow{2}{*}{ NS } \\
\hline & $\mathrm{F}$ & 4.0 & 18.0 & 11.20 & 3.53 & & \\
\hline \multirow{2}{*}{ U1-L1 } & M & 112.0 & 136.0 & 123.10 & 5.93 & \multirow{2}{*}{1.804} & \multirow{2}{*}{ NS } \\
\hline & $\mathrm{F}$ & 111.0 & 134.0 & 122.17 & 5.31 & & \\
\hline \multirow{2}{*}{ L1-OP } & M & 16.0 & 35.0 & 24.66 & 5.12 & \multirow{2}{*}{0.240} & \multirow{2}{*}{ NS } \\
\hline & $\mathrm{F}$ & 16.5 & 35.0 & 25.14 & 4.93 & & \\
\hline \multirow{2}{*}{ L1-MP } & M & 86.0 & 107.0 & 97.84 & 5.41 & \multirow{2}{*}{0.135} & \multirow{2}{*}{ NS } \\
\hline & $\mathrm{F}$ & 85.0 & 108.0 & 98.25 & 5.98 & & \\
\hline \multirow{2}{*}{ U1 to APog mm } & $\mathrm{M}$ & 1.5 & 12.0 & 7.47 & 2.43 & \multirow{2}{*}{0.056} & \multirow{2}{*}{ NS } \\
\hline & $\mathrm{F}$ & 4.0 & 11.0 & 7.37 & 1.98 & & \\
\hline
\end{tabular}

* Measurements in degrees, except for U1 to APog in millimeter

** SD: Standard deviation

*** NS: Not significant at $p \leq 0.05$ 
Table (3): Comparison between Downs' standards for Iraqi adolescents and Downs' original standards for white Americans

\begin{tabular}{|c|c|c|c|c|c|c|c|c|}
\hline \multirow{2}{*}{ Vistatiotes } & \multicolumn{3}{|c|}{ 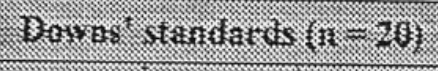 } & \multicolumn{3}{|c|}{ 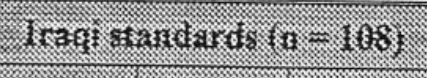 } & \multirow{2}{*}{$f+2=28 ;=$} & \multirow{2}{*}{ 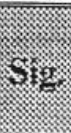 } \\
\hline & Rasage & $y_{1} t_{2}=1$. & S13 & Rasast & 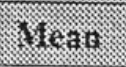 & sio & & \\
\hline \multicolumn{9}{|c|}{ 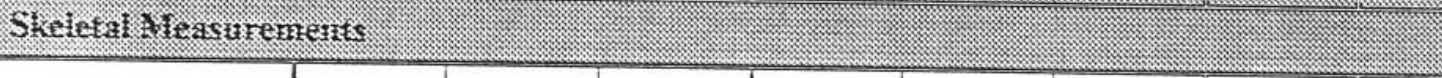 } \\
\hline FH-NPog & $82-95$ & 87.5 & 3.57 & $75-92$ & 84.84 & 3.54 & 3.08 & $\mathrm{~S}^{* *}$ \\
\hline N-A-Pog & $-8.5-10$ & 0 & 5.09 & $-10-13$ & 2.79 & 4.16 & 2.66 & $\mathrm{~S}^{* *}$ \\
\hline AB-NPog & $-9-0$ & -4.6 & 3.67 & $-10-1.0$ & -3.81 & 2.51 & 1.2 & NS \\
\hline MPA & $17-28$ & 21.9 & 3.24 & $20-39$ & 28 & 4.51 & 5.77 & $\mathrm{~S}^{* *}$ \\
\hline FH-SGn & $53-66$ & 59.4 & 3.82 & $55-69.5$ & 62.5 & 3.37 & 3.70 & $\mathrm{~S}^{* *}$ \\
\hline \multicolumn{9}{|c|}{ 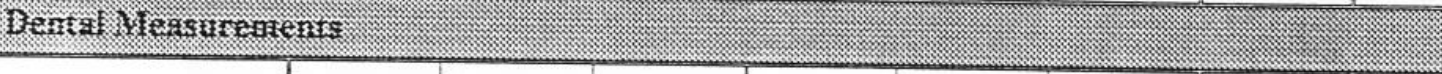 } \\
\hline FH-OP & $1.5-14$ & 9.3 & 3.83 & $4-18.5$ & 11.56 & 3.34 & 2.72 & $\mathrm{~S}^{* *}$ \\
\hline Ul-L1 & $130-150.5$ & 135.4 & 5.76 & $111-135$ & 122.66 & 5.64 & 9.25 & $\mathrm{~S}^{* *}$ \\
\hline L1-OP & $3.5-20$ & 14.5 & 3.42 & $16-35$ & 24.88 & 5.01 & 8.88 & $\mathrm{~S}^{* *}$ \\
\hline L1-MP & $81.5-97$ & 91.7 & 3.78 & $85-108$ & 98.03 & 5.66 & 5.03 & $\mathrm{~S}^{* *}$ \\
\hline Ul to APog mm & $-1-5$ & 1.7 & 3.05 & $1.5-12$ & 7.43 & 2.21 & 9.99 & $\mathrm{~S}^{* *}$ \\
\hline
\end{tabular}

${ }^{*}$ Measurements in degrees except for U1 to APog in millimeters.

$* *$ Highly significant at $\mathrm{p} \leq 0.01, \mathrm{~S}=$ significant, $\mathrm{NS}=$ not significant

$\mathrm{SD}=$ standard deviation

\section{Dental Relationships}

This study showed no significant differences in all dental measurements between Iraqi males and females adolescents for Downs' analysis.

As illustrated in table (3), the result of statistical comparison between combined dental measurements for Iraqi adolescents and white Americans, offered by Downs, showed significant differences at $(p \leq 0.01)$ for all measurements.

The cant of the occlusal plane of the present study was $\left(11.56^{\circ}\right)$, which is greater than the mean value established by Downs on White Americans. This indicate that Iraqi adolescent had steeper occlusal plane in comparison to White Americans. The mean inter-incisal angle U1-L1 was larger in White Americans \& smaller in Iraqi adolescents. This indicates that the Iraqi adolescents had more protrusive upper and lower incisors than the White Americans did. The angle of lower incisor to occlusal plane (L1-OP) was smaller in White Americans \& larger in Iraqi sample. This result 
showed a more positive relation of the lower incisors to the occlusal plane when compared with White Americans. The lower incisor inclination to the mandibular plane (L-MP) was larger in Iraqi sample when compared with that of White Americans. This indicates that the lower incisor was more protrusive in Iraqi adolescents when compared to White American's sample. The distance of upper incisor to subspinale-pogonion plane (U1 to APog) was larger in the Iraqi sample and smaller in the White Americans. This indicates that the upper incisor was more protrusive in Iraqi adolescents as compared to White Americans.

\section{CONCLUSION}

Dentoskeletal measurements showed no significant difference between Iraqi males and females. Comparisons with Downs' original data for white-Americans revealed that Iraqi adolescents are characterized by more backward and downward position of the mandible and steeper mandibular plane when compared to white American subjects. Also the dental pattern of Iraqi adolescents was more protrusive than that of white American subjects. The results of this study support other investigations that a single standard of dento-skeletal relationships is not appropriate for application to different racial and ethnic groups.

\section{REFERENCES}

1. Garcia C. Cephalometric evaluation of Mexican- Americans using the Downs and Steiner analysis. Am J Orthod. 1975; 68: 67-74.

2. Uesato G, Kinoshita Z, Kawamoto T, Koyama I, Nakanishi Y. Steiner cephalometric norms for Japanese \& Japanses Americans. Am J Orthod. 1978; 73: 321-327.

3. Aboul-Azm SF, Fahmy MA. Soft tissue analysis of the face in Egyptian young adults. Alex Dent J. 1980; 5: 85-92.

4. Hajighadimi M, Doughetry $\mathrm{H}$, Garanki. Cephalometric evaluation of Iranian children and its comparison with Tweed's and Steiner's standards. Am J Orthod. 1981; 79: 192-197.

5. Jung S. Steiner cephalometric standards for the Chinese. Am J Orthod. 1981; No1. January (Abstract).

6. Bishara SE, Fernandez A. Cephalometric comparisons of the dentofacial relationships of two adolescent populations from Iowa \& Northern Mexico. Am J Orthod Dentofac Orthop. 1985; 88(4): 314-322.

7. Pereira CB, Galvar AN, Evans WG, Preston CB. A cephalometric evaluation of Brazilian prehistoric man. J Dent Assoc South Af. 1985; 38 (4): 627-631.

8. Park I, Bowman D, Klapper L. A cephalometric study of Korean adults. Am J Orthod Dentofac Orthop. 1989; 96(1): 56-59.

9. Bishara SE, Abdalla EM, Hoppens BJ. Cephalometric comparisons of dentofacial parameters between Egyptian and North American adolescents. Am J Orthod Dentofac Orthop. 1990; 97(5): 413-421.

10. Munandar S, Snow MD. Cephalometric analysis of Deutero-Malay Indonesians. Aust Dent J. 1995; 40(6): 381-388.

11. Miyajima K, McNamara JA, Kimura T Muratas, Lizuka T. Craniofacial structure of Japanese and European American Adults with normal occlusion and well-balanced faces. Am J Orthod Dentofac Orthop. 1996; 110 (4): 431-438.

12. Downs WB. Variations in facial relationships, their significance in treatment and prognosis. Am J Ortho. 1948; 34: 812-840. 
13. Downs WB. The role of cephalometric in orthodontic case analysis and diagnosis. Am J Orthod. 1952; 38: 162-182.

14. Downs WB. Analysis of dentofacial profile. Angle Orthod. 1956; 26: 191-212.

15. Al-Katifi BSh. Prosthodontic cephalometric standards and their relation to facial type in Iraqi adult sample (radiographic cephalometric study). MSc thesis submitted to the College of Dentistry, Baghdad University, 1994.

16. Al-Ta'ani MM. Soft tissue facial profile analysis: A cephalometric study of some Iraqi adults with normal occlusion. MSc thesis submitted to the College of Dentistry, Baghdad University, 1996.

17. Al-Sayagh NM. Dentoskeletal analysis and facial types of Iraqi adults in Mosul City with class I normal occlusion (a lateral radiographic cephalometric study). MSc thesis submitted to the College of Dentistry, Mosul University, 1999. 